\title{
The Developing of CIPP Evaluation Model on the Evaluation of Early Childhood Educator Training in Early Children Education Development Center for Early Children and Community Education North Sumatera
}

\author{
Kristianus Mote \\ Ministry of Research, Technology and Higher Education \\ State University of Medan \\ Indonesia, North Sumatera Province, Medan Town \\ E-Mail: mote.kris@yahoo.com
}

\begin{abstract}
Training evaluation was critical to the competence and quality of training, evaluation was not only carried out at the end of the training but also carried out during the training process from the beginning of the training plan, the middle of training implementation, the end of the training implementation until the post of the training implementation. The purpose of training evaluation was to know and to assess the progress of the training during the training process, starting from the beginning of the training plan, the middle of training implementation, the end of the training implementation until the post of the training implementation. Training evaluation method was qualitative descriptive by using experiment scale, interview, documentation and questionnaire. The results of the training evaluation showed that the evaluation of the training was not in accordance with the evaluation standards of the training implementation because: 1) applying only two out of four stages of training evaluation namely: a) the middle evaluation stage of training implementation. b) the final evaluation stage of training implementation. 2) applying only four out of six evaluated components namely: a) content/training material. b) training resource persons. c) training participants. d) training organizer. 3) applying the training evaluation model, namely Evaluation of CIPP Model. Therefore, it was concluded that it was necessary to: 1) implement four stages of training evaluation, namely: a) the initial evaluation stage of the training plan. b) the middle evaluation stage of the training implementation. c) the final evaluation stage of training implementation. d) post-evaluation stage of training implementation. 2) implement six evaluated components namely: a) achievement of objectives achievement and accuracy. b) content/training materials. c) training resource person. d) training participants. e) training methodology. f) training organizer. 3) implement the evaluation model of the training, the CIPP Model Evaluation that had been developed through research into CIPOOI and develop input aspect namely instrumental input (eight national standard of education) and environmental input (training expert)
\end{abstract}

Keywords-developing of cipp evaluation model, evaluation of educator training of early childhood

\section{INTRODUCTION}

In human resources management there were several functions, one of which was the evaluation function. Training as one of human resources development strategy necessarily required evaluation function in order to know competence of training process starting from the beginning of training plan, middle of training implementation, end of training implementation until post training implementation. Based on the observation indicated that generally the evaluation was done only in the middle of training implementation and the end of the training, whereas the initial evaluation of training planning and post-training implementation were crucial to the competence and quality of the training. It was asserted that a decision-oriented evaluation approach structured provided assistance to administrators or decision-making leaders [1]. The evaluation carried out at the beginning of a training plan called the needs analysis aiming to gather information about capabilities, skill or expertise that would be developed in the training, characteristics of trainees, quality of training materials from relevance and novelty aspects, trainer competence, place of training of participants, infrastructure and facilities needed, accommodation and consumption as well as training schedule, then the evaluation carried out in the middle of the implementation of a training called monitoring process aiming to gather information about how far the program that had been prepared could be implemented properly and correctly. In this monitoring activity, it seeks to assess the quality of the training process, namely: performance of instructors, classroom climate, attitudes and learning motivation of trainees, subsequent evaluation carried out at the end of the training exercise called monitoring results aiming to gather information about the implementation of the process from the beginning of the implementation of the training plan to the middle of the training implementation and then post evaluation of the implementation of training called 
policy analysis aiming to know the change in the performance of participants after returning to their respective workplace. Evaluation was a process of planning, obtaining, and providing information that was essential to making decision alternatives [2]. Evaluation of the program in the context of objectives was as a process of assessing how far the educational objectives could be achieved [3]. Evaluation was an assessment of data collected through assessment activities [4]. Evaluation could be expressed as a decision-making process using information obtained through measurement of learning outcomes, using both test and non-test instruments [5]. Based on the above opinion it could be concluded that evaluation was a systematic and continuous process to collect, describe, interpret and present information to be used as a basis for making decisions, formulate policies and develop the next program. The purpose of evaluation was to obtain accurate and objective information about a program. Those informations could be the process of program implementation, the impacts/outcomes achieved, the efficiency and utilization of the evaluation results that were focused on the program itself, namely to decide whether the program could be continued, repaired or stopped. In addition, it was also used for the purposes of the preparation of the next program or the preparation of policies related to the program. The components that needed to be evaluated in the training included;

1) Achieving goals and objectives accuracy. In the evaluation, there should be the collection of information related to the achievement of goals and objectives accuracy. This meant that whether the training had achieved the expected goals or not and whether the goals were appropriate to the training needs or not .

2) Content or training materials. In the final evaluation, there should be the collection of information relating to the content or materials discussed during the training, included: a) Whether the material covered in accordance with the purpose or not. b) Whether the training material was too simple, too difficult, too theoretical and so forth.

3) Training resource or facilitator. It was also important to gather information about "resource persons or facilitators" that assist in the process of learning activities. In this case it was necessary to gather information concerning the facilitator's skills, the ability of the facilitator in facilitating the training. Things that needed to be evaluated included: a) Mastery and ability to use participatory methods. b) Mastery and understanding of training materials. c) Ability to communicate and interact with participants effectively. d) Teamwork of resource persons or facilitators. e) Ability to use media and training advice effectively.

4) Training participants. The collection of information about participants should also be done in the final evaluation to determine the level of participation of participants, participants cooperation with other participants, participants cooperation the facilitator. In addition, the thing was not less important was the criteria of the participants, whether the participants were involved in the training as expected, as set out in the terms of reference of training and so forth.
5) Training Methodology/Training Effectiveness. Training evaluations also needed to collect information on the use and utilization of methods and their effectiveness. Whether or not the methods were used to encourage the involvement of the participants, whether or not the method used matched to the intended purpose, whether or not the method used was in accordance with the nature and content of training materials.

6) Organizer/Training Committee. The training organizers were very influential on the success of the training that was often ignored. In general, organizers' evaluations focused more on logistic aspects. Things that needed to be evaluated included:: a) Communication, that was on how the notification or invitation was prepared by the exam party, was one type of organizers evaluation, whether the invitation was clear and accompanied by the required information, usually equipped with a training reference framework. b) Supporting training facilities and infrastructure covering the training grounds, for plenary discussions and for group discussions, consumption, accommodation, availability and readiness of materials required by participants, resource persons, committees and others [6]. An evaluation model that had been developed by experts that could be used in evaluating training programs. The following would describe the popular program evaluation model and widely used as a strategy or work guidance in the implementation of program evaluation, namely Evaluation of CIPP Model (Context-Input-Process-Product). The Evaluation CIPP model was a decision- oriented evaluation approach structured to provide assistance to administrators or decisionmaking leaders. The results of the evaluation provided an alternative problem solving for decision makers. This CIPP evaluation model consisted of 4 components as follows: a) Context Evaluation. b) Input Evaluation. c) Process Evaluation. d) Product evaluation [7].

\section{Methods And Results}

\section{A. Methods}

The method used in this research was descriptive analysis research using observation scale, interview, documentation and questionnaire. The research period was 36 months, starting from July 2015 until July 2017. The place of the research was Early Childhood Development and Community Education Center of North Sumatera.

\section{B. Results}

Data of the results, obtained three things as follows:

1) The stages of training evaluation. In the training evaluation, there are two the evaluation stage of the training: a) the middle evaluation stage of the training implementation was called the evaluation stage of the training implementation process. b) the final evaluation stage of training implementation was called the evaluation stage of the training implementation output.

The data descriptions presented in this section include the evaluation data in the middle of the training/training implementation process and the final evaluation data of the training/the output of training implementation. The data was the result of observation, interview, documentation and 
questionnaire to 8. Data descriptions of observations, interviews, documentation and questionnaires are presented in Table 1.1. as the following.

\begin{tabular}{|c|c|c|}
\hline \multirow{3}{*}{ Nu } & \multicolumn{2}{|c|}{ Evaluation Stages } \\
\cline { 2 - 3 } & $\begin{array}{c}\text { In the Middle of Training } \\
\text { Implementation/Training } \\
\text { Implementation Process }\end{array}$ & $\begin{array}{c}\text { The Final of Training } \\
\text { Implementation/Output } \\
\text { Training Implementation }\end{array}$ \\
\hline 01 & $80 \%$ & $70 \%$ \\
\hline
\end{tabular}

Based on table 1.1. it was shown that the results of the evaluation conducted by using the scale of observation, interview, documentation and questionnaire on the middle of the implementation of training/training implementation process were included in the medium category namely $56 \%$.

2) The components which were evaluated in training evaluations. In the training evaluation, there were four (4) components evaluated namely: a) Content/training materials. The description of the data presented in this section included the content data/training materials. The data were the result of observation, interview, documentation and questionnaire to 8 . Description of data of observation, interview and documentation were presented in table 1.2. as the following.

\begin{tabular}{|l|l|c|}
\hline \multirow{2}{*}{ Nu } & \multicolumn{2}{|c|}{ Evaluation Aspects } \\
\cline { 2 - 3 } & $\begin{array}{c}\text { Content Relevance/ } \\
\text { Training materials }\end{array}$ & $\begin{array}{c}\text { Content Review/ } \\
\text { Training materials }\end{array}$ \\
\hline 01 & $80 \%$ & $60 \%$ \\
\hline
\end{tabular}

Based on table 1.2. it was shown that the results of the evaluation conducted by using the scale of observation, interview, documentation and questionnaire on the relevance and reviews of the contents/training materials were included in the low category namely $48 \%$. b) Resource persons/training facilitator. The description of the data presented in this section includes the data of resource persons/training facilitators. The data were the result of observation, interview, documentation and questionnaire to 8. Data descriptions of observations, interviews, documentation and questionnaires were presented in Table 1.3. as the following.

\begin{tabular}{|l|c|c|c|}
\hline \multirow{2}{*}{ Nu } & \multicolumn{3}{|c|}{ Evaluation Aspects } \\
\cline { 2 - 4 } & $\begin{array}{c}\text { Pedagogic } \\
\text { Competence }\end{array}$ & $\begin{array}{c}\text { Personality } \\
\text { Competence }\end{array}$ & $\begin{array}{c}\text { Professional } \\
\text { Competence }\end{array}$ \\
\hline 01 & $80 \%$ & $70 \%$ & $80 \%$ \\
\hline
\end{tabular}

Based on table 1.3. it was shown that the results of evaluation conducted by using the scale of observation, interviews, documentation and questionnaires on pedagogic competence, personal competence and professional competence were included in the low category namely $45 \%$. c) Training participants. The data descriptions presented in this section included the trainee data. The data were the result of observation, interview, documentation and questionnaire. The numbers of people observed, interviewed, documented and questionnaires were 8. Data descriptions of observations, interviews, documentation and questionnaires were presented in Table 1.4. as the following.

\begin{tabular}{|c|c|c|}
\hline \multirow{2}{*}{$\mathrm{Nu}$} & \multicolumn{2}{|c|}{ Evaluation Aspects } \\
\cline { 2 - 3 } & Core Competences & Basic competencies \\
\hline 01 & $70 \%$ & $60 \%$ \\
\hline
\end{tabular}

Based on table 1.4. it was shown that the results of the evaluation conducted by using the scale of observation, interview, documentation and questionnaire on core competencies and basic competencies were included in the low category namely $42 \%$. d) The organizer/training committee. The description of the data presented in this section included the data of the organizer/training committee. The data were the result of observation, interview, documentation and questionnaire to 8. Data descriptions of observations, interviews, documentation and questionnaires were presented in table 1.5. as the following.

\begin{tabular}{|c|c|c|c|}
\hline \multirow{2}{*}{ Nu } & \multicolumn{3}{|c|}{ Evaluation Aspects } \\
\cline { 2 - 4 } & $\begin{array}{c}\text { Personality } \\
\text { Competence }\end{array}$ & $\begin{array}{c}\text { Social } \\
\text { Competence }\end{array}$ & $\begin{array}{c}\text { Managerial } \\
\text { Competence }\end{array}$ \\
\hline 01 & $60 \%$ & $70 \%$ & $80 \%$ \\
\hline
\end{tabular}

Based on table 1.5. it was shown that the results of the evaluation conducted by using the scale of observation, interview, documentation and questionnaire on personal competence, social competence and managerial competence were included in the low category namely $34 \%$.

3) Model used in training evaluation. In the evaluation of training using CIPP model evaluation (Context-Input-ProcessProduct). The data descriptions presented in this section included CIPP model evaluation data. The data were the result of observation, interview, documentation and questionnaire to 8. Data descriptions of observations, interviews, documentations and questionnaires were presented in Table 1.6. as the following.

\begin{tabular}{|l|c|c|c|c|}
\hline \multirow{2}{*}{ Nu } & \multicolumn{4}{|c|}{ The CIPP Model Evaluation } \\
\cline { 2 - 5 } & Context & Input & Process & Product \\
\hline 01 & $70 \%$ & $80 \%$ & $70 \%$ & $60 \%$ \\
\hline
\end{tabular}

Based on Table 1.6. it was shown that the results of the evaluation conducted by using the observation scale, interviews, documentation and questionnaire on the evaluation of CIPP model were included in the low category namely $24 \%$.

\section{FINDING AND DISCUSSION}

\section{A. Discussion}

Based on the description of the data, the discussion was done as follows:

1) Stages of training evaluation. The result of observation, interview, documentation and questionnaire data in the middle evaluation of the training implemenation/training implementation process and final evaluation of training implemenatition/training implementation showed that $100 \%$ was included in high category. This indicated that the middle evaluation of the training implementation/training implementation process and the final evaluation data of the 
training implementation/output of training implementation had the following characteristics: (a) there had been an understanding of the training evaluation stage. (b) there had been a willingness to attempt and to improve the training evaluation stage. Thus, the results of the research had found the initial evaluation stage of training plan/training planning input and post evaluation stage of training implementation/outcome of training implementation. In the training evaluation, four the stage of evaluation of the training was conducted: a) the initial evaluation stage of training planning was called the training input stage. b) the evaluation stage of the middle of the training implementation was called the stage of the training process. c) the final evaluation stage of training implementation was called the training output stage and d) the post-training evaluation stage was called the training outcome stage. The training evaluation stage could be presented in Table 1.7. as the following.

\begin{tabular}{|c|c|c|c|c|}
\hline \multirow[b]{2}{*}{ Nu } & \multicolumn{4}{|c|}{ Evaluation Stages } \\
\hline & $\begin{array}{l}\text { Initial Training } \\
\text { Planning/ } \\
\text { Training } \\
\text { Implementation } \\
\text { Input }\end{array}$ & $\begin{array}{c}\text { Middle } \\
\text { Implementation } \\
\text { Training/ } \\
\text { Training } \\
\text { Implementation } \\
\text { Process }\end{array}$ & $\begin{array}{c}\text { End of Training/ } \\
\text { Training } \\
\text { Implementation } \\
\text { Output }\end{array}$ & $\begin{array}{c}\text { Post } \\
\text { Implementation } \\
\text { Evaluation/ } \\
\text { Training } \\
\text { Implementation } \\
\text { Outcome }\end{array}$ \\
\hline 01 & $100 \%$ & $100 \%$ & $100 \%$ & $100 \%$ \\
\hline
\end{tabular}

Based on table 1.7. it could be concluded that the evaluation stage was not in accordance with the standard evaluation stage of the training.

2) Components which were evaluated in training evaluations. a) Content/training materials. The results of observation, interview and documentation data on the evaluation of the contents/training materials showed that $100 \%$ included in the high category. This indicated that the evaluation of the content/training materials had the following characteristics: (a) there had been an understanding of the content evaluation model/training materials. (b) There had been a willingness to attempt and to improve the evaluation model of the content of the training materials. Thus, the results of the research had found evaluation aspect of content consistency/training content. In the evaluation of the content/training materials, there were three aspects that were evaluated namely a) evaluation aspect of content relevance/training materials. b) evaluation aspect of review contents/training materials. c) evaluation aspect of content consistency/training content. The evaluation aspect of the training content was presented in Table 1.8. as the following.

\begin{tabular}{|l|l|c|c|}
\hline \multirow{2}{*}{ Nu } & \multicolumn{3}{|c|}{ Evaluation Aspects } \\
\cline { 2 - 4 } & $\begin{array}{l}\text { Content Relevance/ } \\
\text { Training materials }\end{array}$ & $\begin{array}{c}\text { Content Review/ } \\
\text { Training materials }\end{array}$ & $\begin{array}{c}\text { Content Consistency/ } \\
\text { Training materials }\end{array}$ \\
\hline 01 & $100 \%$ & $100 \%$ & $100 \%$ \\
\hline
\end{tabular}

Based on Table 1.8. it could be concluded that the evaluation aspect was not in accordance with standard evaluation aspect/training material. b) Resource persons/training facilitators. The results of observation, interview and documentation data on evaluation of resource persons/training facilitators showed that $100 \%$ were included in the high category. This indicated that the evaluation of resource persons/training facilitators had the following characteristics: (a) there had been an understanding of the evaluation model of resource persons/training facilitators. (b) there had been a willingness to try to improve the evaluation model of resource persons/training facilitators. Thus, the results of the study had found evaluation aspects of social competence. In the evaluation of resource persons/training facilitators, there were four aspects evaluated namely a) evaluation aspects of pedagogic competence. b) evaluation aspects of social competence. c) evaluation aspect of personality competence. d) evaluation aspects of professional competence. Evaluation aspects of resource persons/training facilitators were presented in Table 1.9. as the following.

\begin{tabular}{|l|l|l|l|l|}
\hline \multirow{3}{*}{ Nu } & \multicolumn{4}{|c|}{ Evaluation Aspects } \\
\cline { 2 - 5 } & $\begin{array}{c}\text { Pedagogic } \\
\text { Competence }\end{array}$ & $\begin{array}{c}\text { Social } \\
\text { Competence }\end{array}$ & $\begin{array}{l}\text { Personality } \\
\text { Competence }\end{array}$ & $\begin{array}{l}\text { Professional } \\
\text { Competence }\end{array}$ \\
\hline 01 & $100 \%$ & $100 \%$ & $100 \%$ & $100 \%$ \\
\hline
\end{tabular}

Based on table 1.9. it could be concluded that the evaluation aspect was not in accordance with standard evaluation aspect of resource/training facilitator. c) Training participants. The results of observation, interview and documentation data on the evaluation of training participants showed that $100 \%$ were included in the high category. This indicated that the evaluation of the training participants had the following characteristics: (a) there had been an understanding of the training participants' evaluation model. (b) there had been a willingness to try and to improve the evaluation model of the training participants. Thus, the results of research had found the aspects of evaluation of core competencies and evaluation of basic competencies. In the evaluation of the training participants, there are two (2) aspects evaluated namely a) the core competency evaluation aspect. b) basic competence evaluation aspect . The training participants evaluation aspects were presented in Table 1.10. as the following.

\begin{tabular}{|l|c|c|}
\hline \multirow{2}{*}{ Nu } & \multicolumn{2}{|c|}{ Evaluation Aspects } \\
\cline { 2 - 3 } & Core Competence & Basic Competence \\
\hline 01 & $100 \%$ & $100 \%$ \\
\hline
\end{tabular}

Based on table 1.10. it could be concluded that the evaluation aspect was not in accordance with standard evaluation aspect of the training participants. d) The organizer/training committee. The results of observation, interview and documentation data on the evaluation of the organizer/training committee showed that $100 \%$ were included in the high category. This indicated that the evaluation of the training organizer/committee had the following characteristics: (a) there had been an understanding of the evaluation model of the training organizer/committee. (b) there had been a willingness to attempt and to improve the evaluation model of the training organizer/committee. Thus, the results of research had found aspects of evaluation of pedagogical competence and professional competence. In the evaluation of the organizer/training committee, there were five aspects evaluated namely a) pedagogic competence evaluation aspect. b) social competence evaluation aspect. c) personality competence evaluation aspect. d) professional competence 
evaluation aspect. e) managerial competence evaluation aspect. The organizer/training committee evaluation aspects were presented in Table 1.11. as the following.

\begin{tabular}{|l|l|l|l|l|l|}
\hline \multirow{2}{*}{$\mathrm{Nu}$} & \multicolumn{5}{|c|}{ Evaluation Aspects } \\
\cline { 2 - 6 } & $\begin{array}{c}\text { Pedagogic } \\
\text { Competence }\end{array}$ & $\begin{array}{c}\text { Social } \\
\text { Competence }\end{array}$ & $\begin{array}{l}\text { Personality } \\
\text { Competence }\end{array}$ & $\begin{array}{l}\text { Professional } \\
\text { Competence }\end{array}$ & $\begin{array}{l}\text { Managerial } \\
\text { Competence }\end{array}$ \\
\hline 01 & $100 \%$ & $100 \%$ & $100 \%$ & $100 \%$ & $100 \%$ \\
\hline
\end{tabular}

Based on Table 1.11. it could be concluded that the evaluation aspect was not in accordance with standard evaluation aspect of the organizer/training committee.

3) Model used in training evaluation. The results of observation, interview and documentation data on the model used in the training evaluation showed that $100 \%$ were included in the high category. This showed that the model used in training evaluation had the following characteristics: (a) there had been an understanding of the model used in training evaluation. (b) there had been a willingness to attempt and to improve the model used in training evaluation. Thus, the results of the study had found one model to be used as a reference in the implementation of training evaluation. The model used in training evaluation was presented in Table 1.12 below.

\begin{tabular}{|l|c|c|c|c|}
\hline \multirow{2}{*}{ Nu } & \multicolumn{4}{|c|}{ Evaluation of CIPP Model } \\
\cline { 2 - 5 } & Context & Input & Process & Product \\
\hline 01 & $100 \%$ & $100 \%$ & $100 \%$ & $100 \%$ \\
\hline
\end{tabular}

Based on table 1.12. it could be concluded that the model used in training evaluation was not in accordance with the standard of training evaluation model.

\section{B. Finding}

This research was discussed as follows:

1) In the evaluation stage of the training, it was also necessary to add two other evaluation stages a) the initial evaluation stage of the training plan and $b$ ) the post evaluation stage of the training, so that the evaluation stage was in accordance with the standard evaluation stage of the training. The training evaluation stage was presented in Table 1.13. as the following.

\begin{tabular}{|c|c|c|c|c|}
\hline \multirow[b]{2}{*}{ Nu } & \multicolumn{4}{|c|}{ Evaluation Steps } \\
\hline & $\begin{array}{c}\text { nitial of Training } \\
\text { Plan/ } \\
\text { Training } \\
\text { Implementation } \\
\text { Input }\end{array}$ & \begin{tabular}{|c|} 
Middle of \\
Training \\
Implementation/ \\
Training \\
Implementation \\
Process \\
\end{tabular} & $\begin{array}{c}\text { Final of Training } \\
\text { Implementation/ } \\
\text { Training } \\
\text { Implementation } \\
\text { Output }\end{array}$ & $\begin{array}{c}\text { Evaluation of } \\
\text { Post } \\
\text { Implementation/ } \\
\text { Training } \\
\text { Implementation } \\
\text { Outcome }\end{array}$ \\
\hline 01 & $100 \%$ & $100 \%$ & $100 \%$ & $100 \%$ \\
\hline
\end{tabular}

2) In the components evaluated in the training evaluation, it was also necessary to add two training evaluation components, namely: a) the objectives achievement and the objectives accuracy. b) training methodology/training effectiveness so that the components evaluated in the training evaluation were in accordance with the training component evaluation standards. Component of objectives achievement and objectives accuracy and training methodology/training effectiveness, presented in table 1.13a. and 1.13b. as the following.

Table 1.13a. was a component table of the evaluation of objective achievement and accuracy.

\begin{tabular}{|c|c|c|}
\hline \multirow{2}{*}{ Nu } & \multicolumn{2}{|c|}{ Evaluation Components } \\
\cline { 2 - 3 } & $\begin{array}{c}\text { objective } \\
\text { achievement }\end{array}$ & Objective Accuracy \\
\hline 01 & $100 \%$ & $100 \%$ \\
\hline
\end{tabular}

Table 1.13b. was a component evaluation table of training methodologies/training effectiveness.

\begin{tabular}{|l|c|c|c|}
\hline \multirow{2}{*}{ Nu } & \multicolumn{3}{|c|}{ Evaluation Components } \\
\cline { 2 - 4 } & $\begin{array}{c}\text { Individual } \\
\text { Perspective }\end{array}$ & $\begin{array}{c}\text { Group } \\
\text { Perspective }\end{array}$ & $\begin{array}{c}\text { Organizational } \\
\text { Perspective }\end{array}$ \\
\hline 01 & $100 \%$ & $100 \%$ & $100 \%$ \\
\hline
\end{tabular}

3) Evaluation of the CIPP Model, there were four aspects used in training evaluation in accordance with the standard evaluation model of the training. The four aspects in the evaluation model were presented in 1.14. as the following.

\begin{tabular}{|l|c|c|c|c|}
\hline \multirow{2}{*}{ Nu } & \multicolumn{4}{|c|}{ Evaluation Aspect of CIPP Model } \\
\cline { 2 - 5 } & Context & Input & Process & Product \\
\hline 01 & $100 \%$ & $100 \%$ & $100 \%$ & $100 \%$ \\
\hline
\end{tabular}

Evaluation of CIPP Model, the scope of training evaluation was four aspects is: a) context aspect. b) input aspect. c) the process aspect. d) product aspect, the target was not clear, so it needed to be clarified by developing the fifth and six aspects namely the outcome aspect and the income aspect as well as developing the input aspect that was instrumental input (eight national standards of education) and environmental input (training experts) so that the evaluation model of the training was perfect in accordance with the standard evaluation model of the training. The evaluation model was called CIPOOI Model Evaluation. The evaluation model was presented in scheme 1.15. as the following.

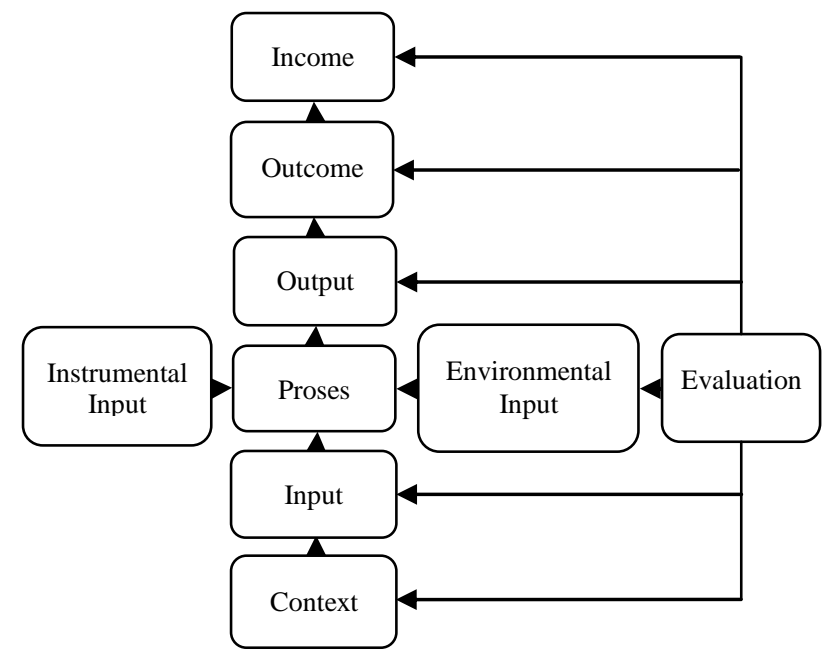

Scheme 1.15. Evaluation of CIPOOI Model 


\section{Description:}

In the training process, it needed to be traversed by six stages, namely: 1) context 2) input. 3) process. 4) output. 5) outcome. 6) income. From the six stages, each had aspects to be evaluated, is:

1) Context. Context background, purpose, strategi education and others to be developed in the system, such as the perceived educational problem and the view of community life.

2) input stages (instrumental input (eight national education standards) and environmental input (training experts)), aspects that were evaluated were: a) the objectives achievement and the objectives accuracy. b) content or training materials. c) resource persons or training facilitators. d) training participants. e) training methodology/training effectiveness. f) organizer/training committee.

3) the process stages, aspects that were evaluated is: a) mastery and ability to use participatory methods. b) mastery and understanding of training materials. c) ability to communicate and interact with participants effectively. d) teamwork of resource persons or facilitators. e) ability to use media and training advice effectively.

4) output stages, the aspects that were evaluated is: a) Pedagogic competence. b) social competence. c) personality competence. d) professional competence. e) managerial competence.

5) outcome stages, aspects that were evaluated namely: a) implementation of pedagogic competence. b) implementation of social competence. c) implementation of personality competence. d) implementation of professional competence. e) implementation of managerial competence.

6) stages of income, aspects that were evaluated is: a) impact of the implementation of pedagogic competence. b) impact of the implementation of social competence. c) impact of the implementation of personality competence. d) impact of implementation of professional competence. e) impact of implementation of managerial competence.

\section{Conlusion}

This research was concluded as follows:

1) There were four stages of training evaluation namely: a) the initial evaluation stage of training plan. b) the evaluation stage in the middle of the training. c) the final evaluation stage of training implementation. d) the evaluation stage of posttraining implementation.

2) There were six components that were evaluated namely: a) objective achievement and accuracy. b) content/training materials. c) resource persons/training facilitator. d) training participants. e) training methodology/training effectiveness. f) organizer/training committee.
3) Evaluation of CIPP Model, the scope of training evaluation included four aspects: a) context, b) input. c) process. d) product.

4) Evaluation of CIPP Model, from four (4) aspects developed into seven aspects: a) analysis. b) context aspect. c) input aspect. d) process aspect. e) output aspect. f) outcome. g) income that was called Evaluation of CIPOOI Model and developed input aspect namely instrumental input (eight national standard of education) and environmental input (expert of training).

\section{Acknowledgment}

In the process of developing the evaluation of this model training, it has been directed, guided and nurtured by various elements so that I would like to thank to elements as follows:

1) Reviewers/authors.

2) Saiful Sagala, as as Professor of Postgraduate Program of Medan State University.

3) Paningkat Siburian, as Professor of Postgraduate Program of Medan State University.

4) Irwan Safii, as Head of Center for Early Childhood Development and Community Education North Sumatera.

5) Irwan Telaumbanua, as Section Head of the Center for Early Childhood Development and Community Education North Sumatera.

6) Djoko Suryono, as Professor of Graduate Program of State University of Malang.

7) Amatus Mote dan Magdalena Tebay, as my Parents. 8) Penina Mote, Bonevasius Mote, Kristina Mote, Bernadeta Mote and Bernarda Mote, as my brothers and sisters. Therefore, it was expected to assist in the process of developing an evaluation model of training in education.

\section{References}

[1] Stufflebeam, D.L. \& Shinkfield, A.J. Systematic Evaluation. Boston: Kluwer Nijhof Publishing. (1985)

[2] Lehmann, H. The Systems Approach to Education. Special Presentation Conveyed in The International Seminar on Educational Innovation and Technology Manila. (1990). Innotech Publications-Vol 20 No. 05.

[3] Tayibnapis, F.Y. Evaluasi Program. Jakarta: Rineka Cipta.

[4] Kumano, Y. 2001. Authentic Assessment and Portfolio Assessment-Its Theory and Practice. Japan: Shizuoka University. (2000).

[5] Zainul \& Nasution. Assessment of Learning Outcomes. Jakarta: Director General of Higher Education. (2001).

[6] Lincoln \& Arifin Zainal. Evaluation of Learning. Bandung: Teens Rosdakarya. (2009).

[7] Nana Sudjana \& Ibrahim. Research and Educational Assessment. Bandung: Sinar Baru Algesindo. (2004). 